\title{
A Study of Wearable Bio-Sensor Technologies and Applications in Healthcare
}

\author{
Amir Mehmood, \\ Department of Computer Science and IT, Federal Urdu University of Arts, Science \\ and Technology, Pakistan \\ aamir.mehmood@fuuast.edu.pk
}

Adnan Nadeem

Department of Computer Science and IT, Federal Urdu University of Arts, Science and Technology, Pakistan \& Faculty of Computer Science and Information System, Islamic University of Madinah, Kingdom of Saudi Arabia adnan.nadeem@fuuast.edu.pk

\section{Kashif Rizwan}

Department of Computer Science and IT, Federal Urdu University of Arts, Science and Technology, Pakistan \& Department of Computer Science, University of Karachi, Pakistan

kashifrizwan@fuuast.edu.pk

\author{
Nadeem Mahmood \\ Department of Computer Science, University of Karachi, Pakistan \\ nmahmood@uok.edu.pk
}

\author{
Ahmad Waqas \\ Department of Computer Science, Sukkur IBA, Sindh, Pakistan \\ ahmad.waqas@iba-suk.edu.pk
}

\begin{abstract}
:
In today's world the rapid advancements in Micro-Electromechanical Systems (MEMS) and Nano technology have improved almost all the aspects of daily life routine with the help of different smart devices such as smart phones, compact electronic devices etc. The prime example of these emerging developments is the development of wireless sensors for healthcare procedures. One kind of these sensors is wearable bio-sensors. In this paper, the technologies of two types of bio-sensors (ECG, EMG) are investigated and also compared with traditional ECG, EMG equipment. We have taken SHIMMERTM wireless sensor platform as an example of wearable biosensors technology. We have investigated the systems developed for
\end{abstract}


analysis techniques with SHIMMERTM ECG and EMG wearable bio-sensors and these biosensors are used in continuous remote monitoring. For example, applications in continuous health monitoring of elderly people, critical chronic patients and Fitness \& Fatigue observations. Nevertheless, early fall detection in older adults and weak patients, treatment efficacy assessment. This study not only provides the basic concepts of wearable wireless bio-sensors networks (WBSN), but also provides basic knowledge of different sensor platforms available for patient's remote monitoring. Also various healthcare applications by using bio-sensors are discussed and in last comparison with traditional ECG and EMG is presented.

Keywords: Wireless Bio-sensors platforms, ECG, EMG, WBSN \& its Applications, SHIMMER $^{\mathrm{TM}}$

\section{Introduction}

Technological advancements in microelectromechanical systems (MEMS) and very large scale integration (VLSI) elevate the field of sensors into more prominent field for research. Therefore the field of wireless sensors is attracting more and more attention from researchers because of its wide range of applications. It has applications in battlefield, sports, agriculture, fitness, structural monitoring, traffic control, underground mining and healthcare. Actually sensors are devices which not only gather the information about the physical property of an object but also gather the changes that occur in the state of that object. These wireless sensors play a key role in healthcare. The sensors used in healthcare have wide range of applications like, remote patient monitoring, rehabilitation process, ambient assistive living and for biofeedback. Most of the sensors used in healthcare are either implanted inside or placed on the human body. The network of these sensors is called Wireless Body area Sensor Network (WBSN). The WBSN comprises of the sensor nodes (wearable or implanted inside the human body), the sink node (also called coordinator) refers to a mobile phone or PDA (Personal Digital Assistant) or relay node and the base station.

The examples of sensors used in WBSN are, implanted cardioverter defibrillators (ICDs), swallowed camera pills, wearable electrocardiography (ECG), electromyography (EMG), electroencephalogram (EEG), blood pressure (BP), Saturation of Peripheral Oxygen $\left(\mathrm{SPO}_{2}\right)$, temperature monitoring sensors, these are the example of physiological sensors or bio-sensors. There are some other types of sensors also used in WBSN, which are inertial based sensors such as accelerometer, gyro meter, magnetometer etc.

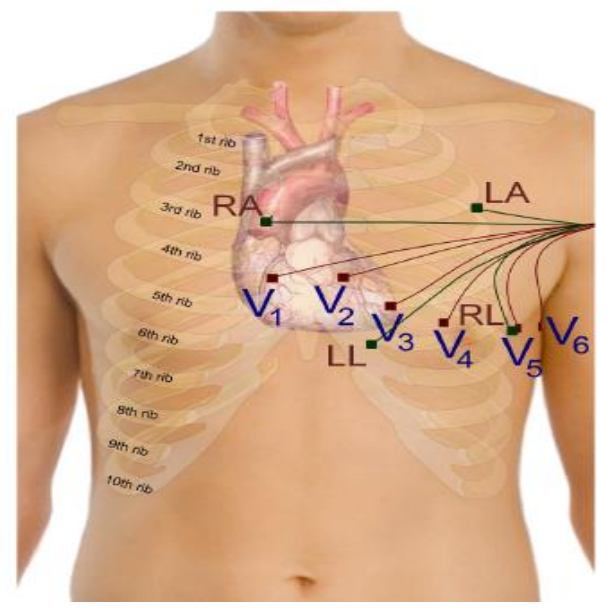

Figure. 1: ECG Electrode Placement Positions [1]

Here in this study, the basic introduction of two bio-sensors (ECG, EMG) is presented. The main reason behind the selection of ECG and EMG is the applications of these two devices in healthcare. The idea behind this study is to investigate different ECG and 
EMG wireless platforms and how it will affect the field of healthcare. ECG and EMG are used to identify the causes behind chronicle diseases such as heart attacks, muscle dysfunction etc.

Electrocardiography (ECG) is the process of capturing the tiny electrical activity of a heart detected through electrodes for a defined time period. These electrodes are placed on the surface of body. ECG is used to detect the disruption in pattern of electrical activity.

A graph comprises of the peak (refers to voltage) versus time is called electrocardiogram. An example of the ECG pulse graph is shown in Figure 2. In each ECG graph all the pulses, duration of these pulses and time interval can be predicted denoted by $\mathrm{P}, \mathrm{Q}, \mathrm{R}, \mathrm{S}, \mathrm{T}$ and $\mathrm{U}$ as depicting in Figure 2. The $\mathrm{P}$ wave is the atrial depolarization with time period of $80 \mathrm{~ms}$ to $100 \mathrm{~ms}$; QRS complex is the depolarization of both right and left ventricles with time period of $80 \mathrm{~ms}$ to $120 \mathrm{~ms}$ (atria repolarization simultaneously), while $\mathrm{T}$ and $U$ waves are ventricular repolarization.

The positions of the placement of ECG electrode is shown in figure 1, where LA (Left Arm), LL (Left Leg), RA (Right Arm) and RL (Right Leg) refer to the bipolar limb leads. In

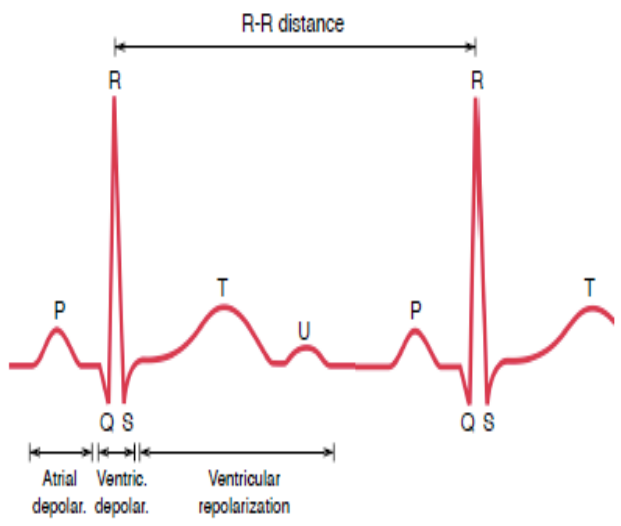

Figure. 2: Typical ECG Pulse [2]
ECG, the term lead refers to the signal of the voltage difference between two electrodes. Figure 3 is also shown the limb leads positions. For ECG in bipolar limb lead configuration, electrodes are normally placed on arms or legs as according to their place mentioned in their names but these electrodes can also be placed as shown in Figure 1. V1, $\mathrm{V} 2, \mathrm{~V} 3, \mathrm{~V} 4, \mathrm{~V} 5$ and V6 are the unipolar leads used for Wilson's Central Terminal (WCT) voltage measurement.

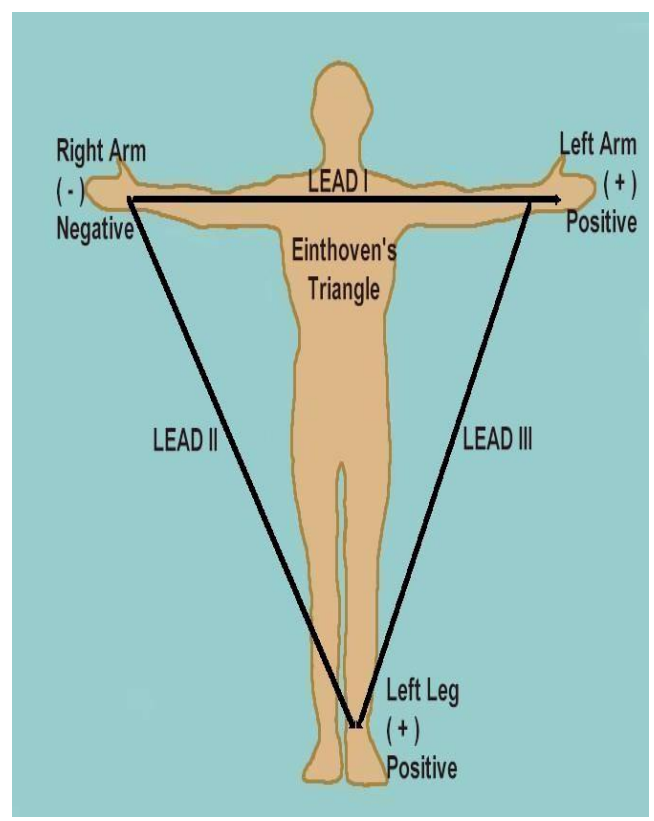

Figure. 3: [The Limb leads]

A diagnostic technique which is used for assessing the condition (health) of skeleton muscles and motor neurons is called Electromyography (EMG) [3] . Motor neurons are nerve cells which control the muscles through transmitting the electrical signal. These electrical signals are detected through tiny electrodes. Intramuscular EMG and skin surface EMG are the two types of EMG. 


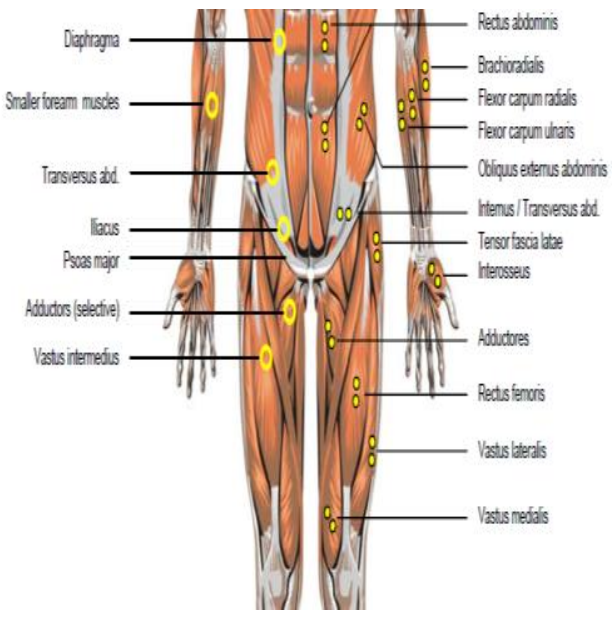

Figure. 4: Anatomical Positions of Selected Electrode Sites, Frontal View [3]

In intramuscular EMG, a needle or fine wire inserted into the muscle tissue for recording the electrical activity and is used for deep muscular analysis. In Skin surface EMG, surface electrodes are adhesively tapped to the skin to measure the electrical activity between two or more points of a surface muscle tissue. EMG can be used for identifying the muscle fatigue, nerve dysfunction and problem in signal transmission from nerves to muscles. Furthermore in this paper, a study related to some available wireless biosensor platforms which are used in different healthcare applications, the technologies and the sensor types used in these platforms is presented. Also in this paper we investigate and discuss the ECG and surface EMG based work has been done so far using SHIMMER ${ }^{\mathrm{TM}}$ sensor platform [4]. The reason behind the selection of SHIMMER ${ }^{\mathrm{TM}}$ sensor platform is its user friendly hardware and software development architecture, which suited for our future and current works in healthcare.

Rest of the paper is organized as follows, next section is Background in which issues and challenges in designing of wireless sensors, various wireless biosensor platforms and different applications of wearable bio sensor are discussed. In section 3, a comparative analysis between traditional ECG, EMG and wearable wireless ECG, EMG sensors is presented and finally the conclusion and future work is discussed.

\section{Background}

There have been several sensor platforms proposed and some are discussed here but before the discussion about sensor platforms, one should know about the issues and challenges associated with the designing and developments of the sensor platforms.

\subsection{Issues and Challenges}

A brief description of some issues and challenges is discussed in the following.

1) Wear-ability: In health care system, the majority of the users are patients. So to design such sensor platforms, one has to keep in mind the comfort and continuous health monitoring of the patients, the wireless sensors must be small in size and lightweight also easily wearable.

2) Energy efficient: As discussed earlier that the sensors used in WBSN are wearable or implanted inside the patient's body, therefore it is either impossible or very difficult to change the energy source of the sensor keeping in mind the discomfort of the patient. Therefore the sensor should be operated in low power. It will increase the lifetime of the sensor.

3) Reliability: Using the wearable wireless bio-sensors in healthcare, reliability is another most important factor in designing of sensor node platform because the treatment of the patients heavily depends on the data acquired from these wearable wireless bio-sensors. Therefore the sensor node platform should be accurate in terms of capturing, filtering and preprocessing of the sensed data. Another aspect also should be considered while talking of reliability i.e. data 
forwarding. A biosensor node should have the ability to forward the sensed data to coordinator.

4) Multi-Hop: In some critical scenarios when patients are not allowed to carry their PDA or mobile phones, then the wireless sensor attached to patients should be able to communicate in multi-hop manner. It means the sensor node not only sense and send its own data but also send the data of a node which is connected only to it or that node is selected for forwarding the data. In some cases the relay node is used for forwarding the sensor node's data.

5) Latency: As discussed earlier these wireless biosensors are used for remote monitoring. Therefore some sensors like ECG, EMG, and BP are most important in the process of treatment. The data acquired from these types of sensors is so critical and needs continuous monitoring. Therefore latency in data should not be tolerated. One has to keep in mind this while designing a sensor platform.

There are some other considerations regarding the designing of a wireless sensor node to develop a WBSN that one needs to keep in mind before designing such platforms. Some of these considerations are Quality of Services QoS, reliability and selforganization. A class based QoS Model [5] which prioritized the data according to sensor types, Reliable Proactive Routing Protocol [6] which ensures the reliability of data sending and receiving, and the study [7], in which authors present the provisioning of the introduction of self-organization in WBSN.

\subsection{Wireless Bio-Sensor Platforms:}

There are several wireless biosensors platforms proposed in past 10 to 15 years.

Piotrowski et. al [8] proposed a microcontroller (MSP430F5438A) based ultra-low power wireless sensor node platform called IHPNode platform. In this proposed sensor node platform, authors used three different types of transceivers which are, European $868 \mathrm{MHz}$ band (radio module $\mathrm{CC} 1101$ ), the $2.4 \mathrm{GHz}$ band (radio module CC2500). The last one contained ZigBee 2.4 $\mathrm{GHz}$ (radio module CC2520). These sensor nodes have two 16 Mbit large flash module and a SD card slot with the support of 2 GB $\mathrm{SD}$ card. In this proposed platform authors considered the monitoring of firefighting scenario. Different types of bio-sensors, inertial sensors, and pressure and temperature sensors are placed on each fire fighter according to their work responsibility. The types of parameter chosen for prototyping are heart rate, blood oxygen saturation, temperature in the fire fighter jacket, air temperature, air humidity, methane concentration, carbon monoxide concentration, air cylinder pressure, orange smoke above, temperature above etc. authors claims the prototype is working fine and ready for use in such other applications.

Chen et al. [9] proposed a low-cost, tiny, lightweight (wearable), ultra-low-power (long lasting), flexible (for research purpose) sensor platform for Wireless Body Area Sensor Network (WBSN). In this architecture, authors used microcontroller (MSP430F1611) for processing and ChipCon CC2420 radio for communication. They developed an electrocardiography (ECG) prototype for initial assessment, and the signal acquired from ECG prototype is transmitted to a PC through a Telos mote, so real time ECG signal will be displayed on PC.

Yamaguchi et al. [10] proposed a low power field programming gate array (FPGA) based sensor node working on $950 \mathrm{MHz}$ frequency. In this microcontroller (MSP430) and FPGA based architecture, authors introduce sensors like, temperature sensor, infrared sensor, sound sensor, light sensor and 3D acceleration based sensor. The main theme of using FPGA is co-processing of the 
acquired data, sensor interface and aggregation of the data. There is no support for physiological sensors.

In [11], authors proposed architecture for ECG home health monitoring, in which they used a sensor node, a relay (hopping) node and a based station node. 3 lead ECG node is made-up with a biopotential amplifier for single supply operation. The relay node is based on low power 8-bit microcontroller PIC18F452. XBee RF Wireless module which has the frequency of $2.4 \mathrm{GHz}$ is used for radio transmission and reception.

In[12], authors proposed a sensor node platform, in which authors introduced two microcontroller based architecture for kinematic sensor with a $\mu \mathrm{SD}$ card for longterm storage of the data. The core microcontroller is Jennic JN5148 which supports IEEE802.15.4 radio transceiver. The other one is ATMega32 which supports USB connectivity. Authors claim that their proposed platform is highly customizable in terms of both the software and hardware and can be integrated with inertial sensors for better results but not supported to the physiological sensors.

Beside above mentioned platforms, some other professionally available platforms are also discussed here.

The BioRadio physiological monitor[13] is a wireless platform used for analysis of different physiological signals such as ECG, EMG, and EEG etc. It works on Bluetooth with range of 10 meter. The maximum data rate is up to $200 \mathrm{Kbps}$. It can continuous works up to 8 hours with memory of $4 \mathrm{~GB}$. The manufacturer claims that it is the best solution for research, physiological signal monitoring and teaching. The major drawback of this platform is it only works on Microsoft Windows 7 or later operating systems (OS). Therefore it is not possible to use it other OS such as MAC or Linux distributions.
BioRadio mote is shown in Figure 5.

Qardiocore[14] is another officially available wearable platform which is used for continuous ECG monitoring. It requires a device compatible with APPLE iOS 9.0 or later only. The most important feature of this device is it is free from wires or patches. It is easy to use with a chest strap as depicted in figure 6.

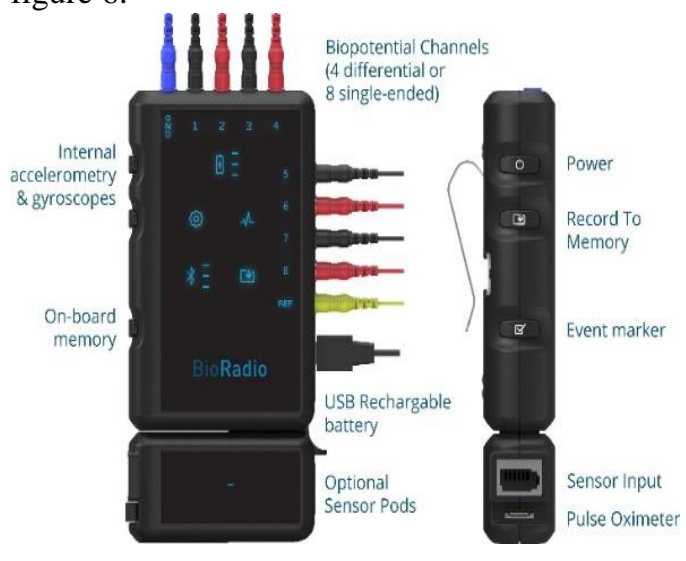

Figure. 5 BioRadio Technology[13]

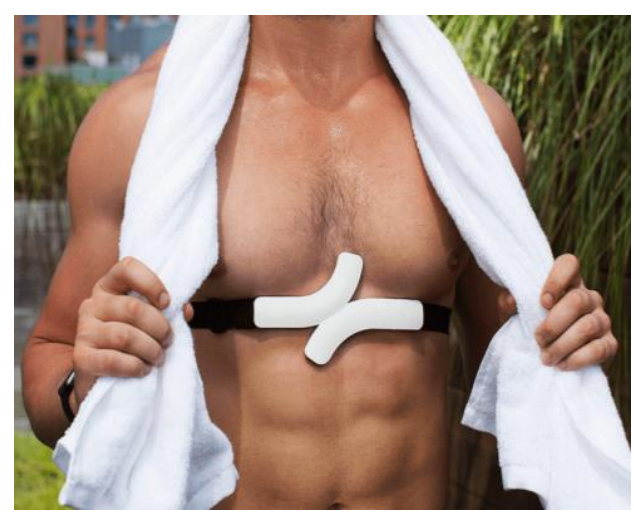

Figure. 6 Qardiocore Technology[14]

BTS analysis system[15] is another system also professionally available platform which is used for analysis of EMG Signals. This system can be used in medical practice, sports and research. Its EMG device BTS FREEEMG is the smallest EMG device in the 
world claimed by its manufacturer. BTSFREEEMG uses Wireless IEEE standard 802.15.4 for wireless data transmission. It can also continuously record the data up to 8 hours.

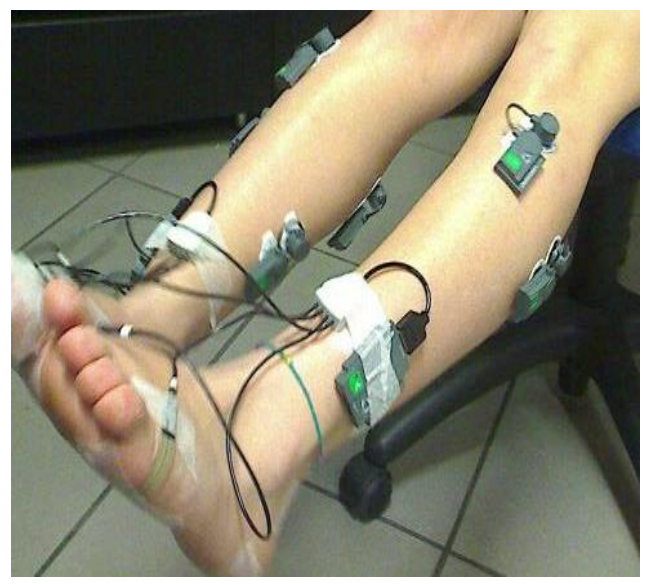

Figure. 7 BTS FREEEMG[15]

Sensing Health with Intelligence, Modularity, Mobility and Experimental Reusability (SHIMMER) [4] is a well reputed wearable sensor platform designed for research and commercial use and well suited for wearable applications. A system developed with Shimmer wearable sensors enables the real time processing, transmission and display of the sensed data with the simple and effective capturing from the body. Shimmer proposes a flexible wireless sensor platform with wide range of application, control over capturing the data, and scientifically reliable data for interpretation and reliable data. It uses MSP430 microcontroller for core computation and ChipCon CC2420 radio for communication. Besides this the micro SD card socket is also given in shimmer devices with the support of 2 GB. Shimmer has the variety of sensing capabilities like kinematic, physiological and ambient sensing through their daughter board add-ons. Shimmer also allows software development in different tools such as C\#, MATLAB, Android and LabVIEW so it can be easily integrated with Shimmer.

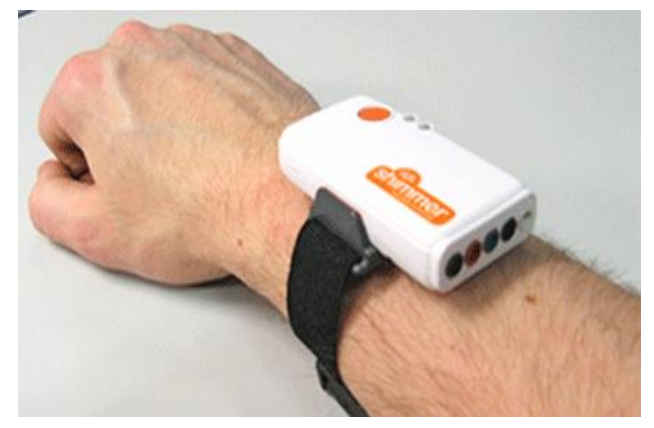

Figure. 8: SHIMMER Mote [4]

\subsection{Application Systems}

In this subsection some ECG and EMG based applications are discussed.

In[16], Android Java-DSP [AJDSP] application was proposed for educational purpose of signal processing courses. The students not only can easily understand the different concepts of signal processing but also test and design their own DSP algorithms and by using different configurations on their android devices. AJDSP can generate Musical Instrument Digital Interface (MIDI) waveforms, Dual Tone Multiple Frequencies (DTMF) waveforms, deterministic and random signals. It can also produce not only the different frequency and time domain signal processing functions but also different algorithms such as Fast Fourier transforms (FFT), z-domain operations and filter design also implemented.

In[17], authors proposed a femtocell based approach to integrate two different types of sensor networks which are Body Sensors Network (BSN) and Ambient Sensors Network (ASN) to provide remote monitoring of a house of patients. In this study, four lead based Shimmer ECG sensors are used for BSN while IRIS mote with MTS400 Sensor Board is used ASN that includes various 
ambient sensors such as humidity and temperature sensors, light sensor, barometric pressure sensors and 2D-accelerometer. The ECG experiment is done through placement of four ECG leads on left arm (LA), left leg (LL), right arm (RA) and right leg (RL) with the rate of sampling frequency set to $512 \mathrm{~Hz}$. Authors used a peak detection algorithm to detect QRS complex and identify the $\mathrm{R}$ peaks correctly with threshold mechanism and finding local maxima in time series, they find out the heart rate of the patient using through identifying the correct $\mathrm{R}$ peak and sampling rate.

In[18] authors present a wearable Shimmer biosensors (ECG and surface EMG) with an Android smartphone based solution for continuous monitoring of patients in daily life. The activity they selected in this study is biking. In this study, standard limb lead II of Einthoven's triangle as shown in figure 3 is selected for ECG data. The electrodes for RA and LL are positioned as given in figure 1. A QRS detection algorithm is used which has different digital signal processing steps processed on raw data of 10 seconds. The first step is band pass filter (comprises of the cascading of low pass and high pass filter) for attenuation of noise, following by 5 steps differentiation, then squaring method and in last moving window integration. With this method author's claim $94.76 \%$ heart beat detection rate for 60 seconds (or 6 samples). In this study EMG is used for treadle detection. The EMG electrodes are placed on the Vastus lateralis and the Vastus medialis muscles as shown in figure 3. Authors claims that the placement of EMG electrodes on these muscles produced satisfactory results. The raw data is processed firstly with squaring for computing the energy of the signals and then moving window process is used for treadle detection. In total of 60 seconds (6 samples with each of the samples comprises of 10 seconds), authors claim $91.25 \%$ detection rate for treadles.
There are some other works have been done so far using Shimmer physiological sensors. For example an ECG based real time allergy detection [19], an EMG based analytical study on BB (bicep brachii) muscles [20], a real time joint angle measurement using EMG [21], an ECG based patient monitoring system [22], athlete ECG monitoring system [23] and activity aware ECG based patient authentication for remote health monitoring [2]. Adnan et. Al [24] highlighted different area in which WBSN can help and also proposed new application areas for WBSN also presented a brief comparison of different sensor applications.

\section{Comparative Analysis}

In this section a comparison between traditional EMG and ECG with wearable wireless biosensor is presented. In some cases the wearable biosensor outperformed their counterparts as shown in table 1.

\subsection{Advantages}

There are some advantages of wearable wireless biosensors discussed here.

1) Flexibility: Compared with traditional ECG and EMG machines, the wireless biosensor are lightweight and easily wearable. A battery is used for power and in most sensors platforms it can be recharged, while traditional ECG, EMG machines require electrical sockets where these machines can be plugged-in.

2) Size: Normally a wearable wireless biosensor is small in size while traditional ECG and EMG are hand handled machines, require some space where they can be placed on especially designed tables or frames.

3) Mobility: The wireless biosensors are lightweight and tiny devices, therefore these can be worn by a patient or person and patient or person can move with ease, while traditional machines are hand-handled, and therefore these are quite difficult to move 
from one place to another while connected with patients.

4) Availability: A person or patient can wear these biosensors at any time and any place without any difficulty, while traditional devices are fixed at one place while connected to patients.

5) Freedom of natural behavior: If a person wants to acquire ECG or EMG through traditional devices, which means he/she should perform some simulated activities. It means that person should be ready for unease environment where he/she cannot feel or identifies it and suggest the patient to take some proactive measures through notification (text message or alarm). This facility can be used in remote monitoring where a message sent to care giver or doctor through smart phone to take some necessary actions.

\section{A. Limitations}

There are some limitation of using these biosensors.

1) Accuracy: Accuracy is one of the biggest factor, sometimes false alarm could be generated. Although some sensor platforms

Table1: Comparison of ECG and EMG (Traditional Vs. Wireless Sensors)

\begin{tabular}{|c|c|c|c|c|c|c|c|c|c|c|}
\hline $\begin{array}{c}\text { ECG } \\
\& \\
\text { EMG } \\
\text { Types }\end{array}$ & $\begin{array}{l}\text { Flexi } \\
\text { bility }\end{array}$ & Size & $\begin{array}{c}\text { Mobility } \\
\text { Type }\end{array}$ & $\begin{array}{c}\text { Availa } \\
\text { bility }\end{array}$ & $\begin{array}{c}\text { Freedo } \\
\mathbf{m}\end{array}$ & $\begin{array}{c}\text { Data } \\
\text { Acquis } \\
\text { ition }\end{array}$ & $\begin{array}{c}\text { Real } \\
\text { time } \\
\text { Soluti } \\
\text { on }\end{array}$ & $\begin{array}{c}\text { Accurac } \\
\mathbf{y}\end{array}$ & $\begin{array}{l}\text { Powe } \\
\mathbf{r} \\
\text { Sourc } \\
\mathbf{e}\end{array}$ & $\begin{array}{c}\text { Conn } \\
\text { ectivi } \\
\text { ty }\end{array}$ \\
\hline $\begin{array}{l}\text { Traditi } \\
\text { onal } \\
\text { Machin } \\
\text { es }\end{array}$ & $\begin{array}{l}\text { No } \\
\text { (in } \\
\text { terms } \\
\text { of fix) }\end{array}$ & $\begin{array}{c}\text { Requi } \\
\text { red } \\
\text { some } \\
\text { Space }\end{array}$ & $\begin{array}{c}\text { Hand } \\
\text { Handled }\end{array}$ & $\begin{array}{c}\text { Only in } \\
\text { particul } \\
\text { ar } \\
\text { places }\end{array}$ & $\begin{array}{l}\text { Not } \\
\text { much }\end{array}$ & $\begin{array}{c}\text { In a } \\
\text { particul } \\
\text { ar time }\end{array}$ & $\begin{array}{c}\text { Once } \\
\text { done, } \\
\text { doctor } \\
\text { will } \\
\text { respo } \\
\text { nd }\end{array}$ & $\begin{array}{l}\text { Very } \\
\text { High }\end{array}$ & $\begin{array}{c}\text { Electr } \\
\text { ical } \\
\text { wall } \\
\text { socket } \\
\text { (unli } \\
\text { mited } \\
\text { ) } \\
\end{array}$ & $\begin{array}{l}\text { Not } \\
\text { requir } \\
\text { ed }\end{array}$ \\
\hline $\begin{array}{c}\text { Wireles } \\
\text { s } \\
\text { Bio- } \\
\text { sensors }\end{array}$ & Yes & $\begin{array}{l}\text { Tiny, } \\
\text { Small }\end{array}$ & $\begin{array}{c}\text { Wearabl } \\
\mathrm{e}\end{array}$ & $\begin{array}{c}\text { Anywh } \\
\text { ere }\end{array}$ & Yes & $\begin{array}{c}\text { Anywh } \\
\text { ere }\end{array}$ & $\begin{array}{c}\text { Yes } \\
\text { (any } \\
\text { time ) }\end{array}$ & $\begin{array}{c}\text { Low } \\
\text { Compare } \\
\text { to } \\
\text { Traditio } \\
\text { nal } \\
\end{array}$ & $\begin{array}{c}\text { Batter } \\
y \\
\text { (Limit } \\
\text { ed) }\end{array}$ & $\begin{array}{c}\text { Requi } \\
\text { red }\end{array}$ \\
\hline
\end{tabular}

express his/her feelings with freedom according to his/her own will. In contrast to this a person or patient can do routine work while connected with wearable bio sensors.

6) Any time data acquisition and monitoring: Wearable biosensors enable the acquisition of real time data at any time and any place. Therefore, it allows the real time monitoring of the patient. While traditional machines do not have these type of luxuries.

7) Real time solution: A bio sensor work by a patient can send the data to patient's smart device (smart phone) for continuous monitoring. With the help of smart computing devices where some anomaly detection algorithms, if any anomaly in pattern of acquired data is found then the device claim that their sensors are $99 \%$ accurate but there is always a chance, for example misplacing the electrodes or electrodes are not adhesively tapped with body.

2) Power source: Batteries are used in these wireless sensors for powering the sensors, which became discharged so either these batteries should be replaced or recharged. The patient may feel uncomfortable when the battery of the sensor is either changed or recharged. It is also to be remembered that the smart device has also a battery which also needs to be charged due to continue receiving (also some sending) the data from sensors and computation which are battery discharging processes. 
3) Connectivity: It is also recommended that when using a wearable wireless bio Table sensors are used, the connectivity between smart phone and the sensors should be wellmaintained otherwise the crucial data may be lost

\section{Conclusion and Future Direction}

In today's world, the importance of wireless sensors in an individual's life is increasing rapidly. Therefore, this field has emerged as one of the top most research area. In this study, two types of biosensors (ECG, EMG) are selected to discuss because of their applications in healthcare. In first, some basic knowledge of ECG and EMG is presented. Then some already proposed physiological wireless sensors platforms are presented. Besides this, a detailed discussion is presented about the issues and challenges facing in designing and developments of wireless sensors especially for healthcare applications. There are some applications based on SHIMMER $^{\mathrm{TM}}$ sensor platform also discussed. In last, ECG and EMG sensors are compared with traditional ECG and EMG equipment in terms of different parameters. In future, SHIMMER $^{\mathrm{TM}}$ IMU (Inertial Measurement Unit) and SHIMMER ${ }^{\mathrm{TM}}$ EMG will be used for fall detection and fall risk assessment in elderly.

\section{References}

[1] http://www.shimmersensing.com/images/u ploads/docs/ECG_User_Guide_Rev1.11.pdf

[2] Sriram, J. C., Shin, M., Choudhury, T., \& Kotz, D. (2009, November). Activity-aware ECGbased patient authentication for remote health monitoring. In Proceedings of the 2009 international conference on Multimodal interfaces (pp. 297-304). ACM.
[3] Konrad, P. (2005). The abc of emg. A practical introduction to kinesiological electromyography, 1, 30-35.

[4] Burns, A., Doheny, E. P., Greene, B. R., Foran, T., Leahy, D., O'Donovan, K., \& McGrath, M. J. (2010, August). SHIMMER ${ }^{\text {TM: }}$ an extensible platform for physiological signal capture. In 2010 Annual International Conference of the IEEE Engineering in Medicine and Biology (pp. 37593762). IEEE.

[5] Salam, A., Nadeem, A., Ahsan, K., Sarim, M., \& Rizwan, K. A class based QoS model for Wireless Body Area Sensor Networks. Research Journal of Recent Sciences_ISSN, 2277, 2502.

[6] Khan, O. U. O., Nadeem, A., \& Ahsan, K. RPRP: Reliable Proactive Routing Protocol for Wireless Body Area Sensor Network. J. Basic. Appl. Sci. Res., 4(8) 17-25, 2014. ISSN 2090-4304.

[7] Mehmood, A., \& Nadeem, A. (2016). SelfOrganized Routing in Body Area Sensors Networks: A Review, Analysis and Simulationbased Case Study. Pak. J. Engg. \& Appl. Sci. Vol. 19, July, 2016 (p. 26-44).

[8] Piotrowski, K., Ortmann, S., \& Langendörfer, P. (2012). Multi-radio wireless sensor node for mobile biomedical monitoring. Biomedical Engineering/Biomedizinische Technik, 57(SI-1 Track-L), 725-728.

[9] Xijun, C., Meng, M. H., \& Hongliang, R. (2006, January). Design of sensor node platform for wireless biomedical sensor networks. In 2005 IEEE Engineering in Medicine and Biology 27th Annual Conference (pp. 4662-4665). IEEE.

[10] Yamaguchi, S., Miyazaki, T., Kitamichi, J., Guo, S., Tsukahara, T., \& Hayashi, T. (2013, November). Programmable wireless sensor node featuring low-power FPGA and microcontroller. In Awareness Science and Technology and UbiMedia Computing (iCAST-UMEDIA), 2013 International Joint Conference on (pp. 596-601). IEEE.

[11] Rashid, R. A., Rahim, M. R. A., Sarijari, M. A., \& Mahalin, N. (2008, December). Design and 
implementation of Wireless Biomedical Sensor Networks for ECG home health monitoring. In Electronic Design, 2008. ICED 2008. International Conference on (pp. 1-4). IEEE.

[12] Scholl, P. M., Van Laerhoven, K., Gordon, D., Scholz, M., \& Berning, M. (2012, June). Jnode: a sensor network platform that supports distributed inertial kinematic monitoring. In Networked Sensing Systems (INSS), 2012 Ninth International Conference on (pp. 1-4). IEEE.

[13] https://glneurotech.com/bioradio/wirelessphysiological-monitor/

[14] https://www.getqardio.com/qardiocorewearable-ecg-ekg-monitor-iphone/

[15] http://www.btsbioengineering.com/produc ts/surface-emg/bts-freeemg/

[16] Rajan, D., Spanias, A., Ranganath, S., Banavar, M. K., \& Spanias, P. (2013, October). Health monitoring laboratories by interfacing physiological sensors to mobile android devices. In 2013 IEEE Frontiers in Education Conference (FIE) (pp. 1049-1055). IEEE.

[17] Maciuca, A., Stamatescu, G., Popescu, D., \& Struţu, M. (2013, August). Integrating wireless body and ambient sensors into a hybrid femtocell network for home monitoring. In Systems and Computer Science (ICSCS), 2013 2nd International Conference on (pp. 32-37). IEEE.

[18] Richer, R., Blank, P., Schuldhaus, D., \& Eskofier, B. M. (2014, June). Real-Time ECG and EMG Analysis for Biking Using Android-Based Mobile Devices. In 2014 11th International Conference on Wearable and Implantable Body Sensor Networks (pp. 104-108). IEEE.

[19] Rivas, R. G., Domínguez, J. J. G., Marnane, W. P., Twomey, N., \& Temko, A. (2013, September). Real-time allergy detection. In Intelligent Signal Processing (WISP), 2013 IEEE 8th International Symposium on (pp. 21-26). IEEE.

[20] Ahamed, N. U., Sundaraj, K., Ahmad, R. B., Rahman, M., \& Islam, M. A. (2012). Analysis of right arm biceps brachii muscle activity with varying the electrode placement on three male age groups during isometric contractions using a wireless EMG sensor. Procedia Engineering, 41, 61-67.

[21] O'Donovan, K., \& Ayer, S. (2011, November). Real-time joint angle measurement using the shimmer wireless sensor platform. In Proceedings of the First ACM Workshop on Mobile Systems, Applications, and Services for Healthcare (p. 7). ACM.

[22] Chen, B., Varkey, J. P., Pompili, D., Li, J. K., \& Marsic, I. (2010, March). Patient vital signs monitoring using wireless body area networks. In Bioengineering Conference, Proceedings of the 2010 IEEE 36th Annual Northeast (pp. 1-2).

[23] Imaiyan.C.R., Ragavi.S.R, and Dr. Suganthi ,L. (2015, January) “Athlete's ECG Monitoring System using Wireless Sensor Networks", International Journal on Applications in Medical Science and Research Volume 1: Issue 1:, pp 1-3.

[24] Nadeem, A., Hussain, M. A., Owais, O., Salam, A., Iqbal, S., \& Ahsan, K. (2015). Application specific study, analysis and classification of body area wireless sensor network applications. Computer Networks, 83, 363-380. 